\title{
Compreensão social do Envelhecimento e Velhice: análise semiolinguística de um dispositivo técnico ${ }^{1}$
}

\section{Social understanding of Aging and Old Age: a semiolinguistic analysis of a technical device}

\author{
Karine Kátia Iria Luiz² \\ Maria das Dores Saraiva de Loreto $^{3}$ \\ Marco Aurélio Marques Ferreira ${ }^{4}$ \\ Simone Caldas Tavares Mafra ${ }^{5}$
}

\section{Resumo}

Buscou-se analisar a compreensão social do envelhecimento e da velhice apresentada em um dispositivo técnico, trazendo à tona o imaginário sobre o idoso que foi defendido no discurso, os argumentos utilizados para retratar essa etapa da vida e as técnicas argumentativas usadas para convencer o leitor, por meio da análise semiolinguística do discurso, baseada em Charaudeau. O texto se enquadra na modalidade elocutiva e no modo de raciocínio baseado na Concessão Restritiva, Dedução por Cálculo, Explicação Pragmática e Associação dos Contrários. Compreendeu-se que o idoso é um cidadão de direitos, cujas necessidades variam conforme as condições socioeconômicas, culturais, familiares e de saúde; e que o Estatuto do Idoso trouxe avanços, no que diz respeito a como o idoso deve ser tratado na sociedade, e contradições, ao propor medidas que podem gerar conflitos intergeracionais. Esta análise permitiu uma melhor reflexão sobre políticas públicas e para se pensar o idoso na sociedade contemporânea.

Palavras-chave: Idoso; Análise do Discurso; Políticas Públicas.

\begin{abstract}
We sought to analyze the social understanding of aging and old age brought into a technical device, bringing to light the imaginary about the elderly that was defended in the speech, the arguments used to portray this stage of life and the argumentative techniques used to convince the reader, through the semiolinguistic analysis of discourse, based on Charaudeau. The text fits in the elocutive modality and mode of reasoning based on the Restrictive Concession, Calculation Deduction, Pragmatic Explanation and Association of Contraries. It was understood that the elderly is a citizen of rights, whose needs vary according to socioeconomic, cultural, family and health conditions and that the Elderly Statute has brought advances as to how the elderly should be treated in society and contradictions, when proposing measures that can generate intergenerational conflicts. This analysis allowed a better reflection on public policies and to think about the elderly in contemporary society.
\end{abstract}

Keywords: Elderly; Discourse Analysis; Public Policies.

\footnotetext{
${ }^{1}$ Este artigo apresenta os resultados parciais de uma tese em andamento.

2 Doutoranda, Mestra e Graduada em Economia Doméstica pela Universidade Federal de Viçosa. E-mail: karine.iria@ufv.br

3 Doutora em Economia Aplicada pela Universidade Federal de Viçosa. Professora do Programa de Pós-Graduação em Economia Doméstica da Universidade Federal de Viçosa. E-mail: mdora@ufv.br

4 Doutor em Economia Aplicada pela Universidade Federal de Viçosa. Professor do Programa de Pós-Graduação em Administração da Universidade Federal de Viçosa. E-mail: marcoufv1@gmail.com

${ }^{5}$ Doutora em Engenharia de Produção pela Universidade Federal de Santa Catarina. Professora do Programa de Pós-Graduação em Economia Doméstica da Universidade Federal de Viçosa. E-mail: sctmafra@ufv.br
} 


\section{INTRODUÇÃO}

Conhecer a inter-relação entre as circunstâncias que envolvem determinado fato ou situação é primordial para análise coerente da realidade social. $O$ envelhecimento humano é permeado por questões que requerem enfrentamento adequado, afinal, as evidências empíricas vêm mostrando que a expectativa de vida no Brasil tem aumentado paulatinamente e ocasionado mudanças no perfil demográfico. Estima-se que, em futuro próximo, haja mais idosos que jovens em virtude da redução tanto da taxa de natalidade quanto da mortalidade.

Informações sobre indicadores sociais e demográficos divulgados anualmente pelo IBGE alertam que o grupo de idosos é, atualmente, um contingente populacional significativo, em termos absolutos e de crescente importância relativa no conjunto da sociedade brasileira, derivando novas exigências e demandas de políticas públicas de saúde e de inserção ativa dos idosos na vida social (IBGE, 2015).

Percebe-se, no entanto, que os idosos estão se destacando não somente pelo aumento quantitativo, mas pelas consequências de uma população envelhecida. $O$ reconhecimento da heterogeneidade do processo de envelhecimento e da diversidade de experiências dos que o vivem é capaz de construir modos de pensar, sentir e agir, possibilitando, ou não, a criação de condições para enfrentar os desafios da velhice. Nesse sentido, Jardim, Medeiros e Brito (2006) concordam que definir velhice usando apenas a visão biológica é um equívoco de demarcação meramente cronológica, pois trata a população idosa de forma homogênea, não levando em consideração aspectos importantes do contexto sociocultural em que os idosos estão inseridos.

Por esse motivo, os estudos direcionados a essa temática podem ser encontrados em diferentes áreas de conhecimento e com enfoques variados, dependendo da intenção dos pesquisadores. Essa intenção perpassa a noção de construção da realidade, e os sujeitos envolvidos trazem consigo ideias preconcebidas ou interiorizadas, refletindo suas motivações. Tem-se, assim, uma variedade de discursos - políticos, econômicos, religiosos, médicos, higienistas, entre outros - propondo reflexões e soluções para a vivência do envelhecimento.

Tomando por base essa realidade, o objetivo deste estudo foi analisar a compreensão social do envelhecimento e velhice veiculados em um dispositivo técnico. Para tal, buscou-se trazer à tona o imaginário sobre o idoso que foi defendido em discurso, os argumentos utilizados para retratar essa etapa da vida e as técnicas argumentativas empregadas para convencer o leitor. 


\section{REVISÃO DE LITERATURA}

O envelhecimento populacional traz à tona a necessidade de se adentrar nesta realidade, buscando compreendê-la para então buscar soluções para os problemas a serem enfrentados, bem como para tirar proveito das oportunidades que surgem em decorrência desse fato. $O$ processo de envelhecimento demográfico, de acordo com Siqueira, Botelho e Coelho (2002), repercute nas diferentes esferas da estrutura social, econômica, política e cultural da sociedade, uma vez que os idosos, bem como os demais segmentos etários, possuem demandas específicas para obtenção de adequadas condições de vida. Rebouças et al. (2013) ressaltam que o aumento de pessoas mais velhas acontece simultaneamente com a ampliação da classe média brasileira, impactando na possibilidade de acesso ao consumo de determinados bens e serviços.

O envelhecimento vem sendo associado à imagem positiva de se viver mais e melhor. No entanto, essa realidade não se concretiza para todos os cidadãos, de modo que nas sociedades capitalistas, marcadas pela desigualdade distributiva, surgem novos desafios ligados às camadas mais pobres e ao lugar a ser ocupado pelos novos e novíssimos velhos (REBOUÇAS et al., 2013). Essa realidade foi confirmada por Alvino (2015), que ressaltou o fato de que o aumento no número de idosos no Brasil ainda não pode ser considerado uma conquista da sociedade, uma vez que os resultados de sua pesquisa demonstraram que diversos problemas caracterizam a relação dos idosos com a família, a comunidade, o governo e a sociedade. Afirma ainda que o idoso brasileiro vive uma realidade diversificada e marcada por formas plurais de existência, encontrando o despreparo da sociedade em lidar com o envelhecimento humano e garantir a sua cidadania.

Um fato importante a ser destacado é de que a rápida mudança na estrutura etária brasileira, de acordo com Mafra et al. (2013), chama a atenção para o enfrentamento de alguns problemas básicos relacionados com a ineficiência das políticas públicas e sociais voltadas para o processo do envelhecimento. Tal ineficiência se faz perceber no tratamento dado às famílias e no que se espera delas, no que diz respeito ao cuidado dos idosos. Camarano e Kanso (2010) alertam para o fato de que, embora a legislação brasileira estabeleça que o cuidado dos membros dependentes deva ser responsabilidade das famílias, a redução da fecundidade, as mudanças na nupcialidade e a crescente participação da mulher no mercado de trabalho fazem que esse cuidado se torne cada vez mais escasso, requerendo que o Estado e o mercado privado dividam com ela essa responsabilidade. 
Silva e Almeida (2015) também comentam sobre essa realidade, enfatizando que, embora a família seja considerada extremamente importante na vida dos seus idosos, o convívio familiar pode gerar conflitos e, nesse caso, é necessário que seus integrantes entendam o comportamento dos seus idosos. Comentam também que, apesar de a obrigação do cuidado ao idoso primeiramente ser da família, esta pode não estar preparada para esse papel, devendo o poder público e a sociedade assegurarem ao idoso, com absoluta prioridade, a efetivação do direito à vida, à saúde, à alimentação, à educação, à cultura, ao esporte, ao lazer, ao trabalho, à cidadania, à liberdade, à dignidade, ao respeito e à convivência familiar e comunitária (SILVA; ALMEIDA, 2015).

Nesse mesmo sentido, Souza, Skubs e Bretas (2007) confirmam que a grande importância da família, diante do cuidado para com o seu idoso, torna necessário o entendimento de como ela vem conseguindo, ou não, responder às necessidades dessa população. Assim, é preciso que haja readequação das estratégias que visam assistir o idoso e sua família, buscando atender às necessidades reais de cuidado e otimizando uma relação harmônica entre idoso e família, por meio de políticas públicas direcionadoras do cuidado ao idoso em domicílio (BRITO et al., 2014).

Reconhece-se que há uma parcela considerável da população idosa com dificuldades em ouvir, enxergar, subir escadas e lidar com as atividades básicas do cotidiano, demandando cuidados que, no caso brasileiro, recaem em quase toda a sua totalidade sobre a família, principalmente sobre as mulheres. Sobre isso, Melchioree et al. (2013) evidenciam que o apoio social tem forte impacto sobre os indivíduos, principalmente nos mais velhos com problemas de saúde. Uma rede de apoio ineficiente e relações familiares ou sociais precárias podem ser cruciais e representam fatores de risco para o abuso de idosos. Esses fatores de risco se agravam na iminência de um Estado que presta serviços, mas que não assume as necessidades da população idosa e sua família, deixando-as sem respostas sociais adequadas (SILVA; ALMEIDA, 2015).

Flores et al. (2010) corroboram essa questão, concluindo que a presença constante da família não é necessariamente manifestação de cuidado, podendo até mesmo representar falta de cuidado com o idoso. Esses autores alertam ainda que necessitamos de cuidados ao nascer e ao morrer, mas a qualidade do cuidado depende do respeito às especificidades culturais do grupo social em que ele é exercido, constatando-se que tal ação é intergeracional, tendo em vista que o ser humano é um ser social e que o estabelecimento de vínculos no seu mundo afetivo é fundamental. 
Nesse sentido, Camacho e Alves (2015) observam a importância de tornar viável a interação entre as gerações de jovens, idosos e a própria família em si, indo ao encontro do que Flores et al. (2010) afirmam, ou seja, o cuidado intergeracional pode vir a ser uma experiência prazerosa, dependendo das relações entre as pessoas e dos significados atribuídos ao idoso e ao cuidado, o que influencia as atitudes de todas as gerações. Também Souza, Skubs e Bretas (2007) compreendem que o significado do processo de envelhecimento, no âmbito da família intergeracional, é construído pelos seus membros no decorrer da vida em comum e é composto pelas peculiaridades de cada arranjo familiar, expresso pela cultura e pelas histórias individuais e coletivas. Marques e Souza (2012), por sua vez, sugerem que o desenvolvimento familiar está diretamente relacionado ao modo como as diferentes gerações da família buscam se adaptar aos diversos estádios da vida familiar, em que ocorre rearranjo contínuo de papéis, organização de pertenças e distâncias.

Segundo Lima (2007), além da boa convivência familiar, as percepções sociais sobre o envelhecimento podem gerar mudanças e ter impacto positivo na autoimagem dos idosos. A aproximação física e afetiva com o diferente e o convívio com outras gerações são caminhos frutíferos para enfraquecer qualquer tipo de discriminação. Além disso, é preciso considerar, de acordo com Rebouças et al. (2013), que doença e declínio físico e mental são fenômenos vividos, de maneira heterogênea, entre as pessoas. Abreu (2017, p. 42) afirma que, embora o envelhecimento acarrete desgaste dos sistemas fisiológicos de quem envelhece, com diminuição das capacidades biológicas, isso não, necessariamente, acontece com a capacidade psicológica e social; isto é, com a "capacidade de desenvolver e de expressar interesses, vivenciar afetos e considerar mudanças oportunidades a serem exploradas".

Caradec (2016), por sua vez, considera que a idade avançada possui fortes contrastes, pois, enquanto uns sofrem alguma deficiência considerável, outros envelhecem, escapando das limitações funcionais e de outras tantas, e assim, apesar das dificuldades físicas encontradas, conseguem se adaptar. Esse autor considera ainda que essa diversidade de situações está relacionada com as condições econômicas de quem envelhece, afirmando que "as pessoas de classes abastadas desfrutam ao mesmo tempo de uma expectativa de vida mais elevada e de melhor estado de saúde" (CARADEC, 2016, p. 21).

Para Camarano, Kanso e Melo (1999), a relação entre envelhecimento e dependência não é tão clara, uma vez que parcela expressiva de indivíduos, considerados idosos, ainda está em pleno vigor físico, com boa saúde e inserida no mercado de trabalho, mesmo estando 
aposentada, assumindo papéis não esperados, como o de suporte a outros membros da família, especialmente filhos adultos.

Essa questão é também discutida por Barros, Mendonça e Santos (1999), que relatam que a evolução dos rendimentos da população ao longo do seu ciclo de vida cresce com a idade, até cerca de 60 anos, e vai declinando a partir de então. A composição da renda domiciliar muda, significativamente, com a idade, de modo que entre os idosos as rendas de aposentadoria constituem a parcela principal. Para os idosos pobres, o valor referente à aposentadoria é, particularmente, importante, indicando que sua presença na família, com os não idosos, é responsável por diminuir seu grau de pobreza, que seria maior, caso os idosos constituíssem domicílios. Outrossim, é importante levar em conta, conforme enfatizam Camargos, Machado e Rodrigues (2006), que, deixando de lado a questão das preferências e pensando que morar sozinho pode ser uma realidade a que o idoso tenha que se submeter, seja por necessidade, seja por abandono, é preciso pensar as políticas de apoio a essa população, principalmente para aquelas de classes socioeconômicas inferiores.

Veras (2009) chama a atenção para o fato de que, embora o prolongamento da vida seja desejo de qualquer sociedade, ele só pode ser considerado como real conquista à medida que se agregue qualidade aos anos adicionais de vida. Para ele, qualquer política destinada aos idosos deve levar em conta SUA a capacidade funcional e a necessidade de autonomia, de participação, de cuidado, de autossatisfação. Para que isso ocorra, Souza, Skubs e Bretas (2007) indicam que o caminho é a busca de conhecimento sobre o processo de envelhecimento, que torna possível a compreensão das necessidades dos idosos, de modo que o cuidado para com eles seja agilizado e melhorado na qualidade. Da mesma forma, Joia, Ruiz e Donalisio (2007) confirmam que o aumento da sobrevida da população traz consigo a necessidade de garantir aos idosos não apenas maior longevidade, mas felicidade, qualidade de vida e satisfação pessoal.

\section{ENFOQUE METODOLÓGICO}

De acordo com Charaudeau (2005), a análise semiolinguística do discurso é uma teoria que procura relacionar os fatos de linguagem a fenômenos psicológicos e sociais. É chamada de semiolinguística pelo fato de que a construção do sentido, bem como sua configuração, ocorre numa relação forma-sentido, sob a responsabilidade de um sujeito intencional, que busca influenciar socialmente um contexto determinado. O quadro metodológico desenvolvido por esse 
autor parte do pressuposto de que a análise do discurso é empírico-dedutiva e deve determinar seus objetivos em relação ao tipo de objeto construído. Propõe a construção de uma tipologia que considere as condições de realização dos textos, ou seja, os contratos de comunicação.

A instrumentação e os procedimentos de análise variam conforme o texto (mono ou dialógico), as matérias semiológicas e a estratificação do objeto e, ainda, leva em conta qual instrumentação adotar, dependendo do quadro teórico e das hipóteses metodológicas. Assim, para a realização da análise do discurso, baseada em Charaudeau, foram examinados os seguintes aspectos: situação de comunicação, finalidade do discurso, estratégias de ordem enunciativa e procedimentos de ordem argumentativa sobre a compreensão do envelhecimento e da velhice.

Dessa forma, levando em conta o envelhecimento populacional e a questão social em torno da velhice, buscou-se identificar um corpus que permitisse analisar a percepção do envelhecimento e da velhice em um dispositivo técnico, intitulado "Estatuto do Idoso: avanços com contradições". O texto produzido por Ana Amélia Camarano discute os avanços e contradições de algumas ações propostas pelo Estatuto do Idoso, que estava às vésperas de completar 10 anos.

\section{RESULTADOS E DISCUSSÃO}

\section{Identidade dos Participantes: situação de comunicação}

De acordo com Charaudeau (2008), a representação do dispositivo da encenação da linguagem contém aspectos do espaço externo da situação comunicacional e do espaço interno do dizer. Nesse sentido, o espaço externo neste corpus identifica os parceiros em um processo de produção da linguagem: o locutor ou o sujeito comunicante, como aquele que está por trás da formação da pesquisadora, no caso o Instituto de Pesquisa Econômica Aplicada (IPEA), que Ana Amélia Camarano representa. O receptor ou o sujeito interpretante são os profissionais especializados e todos os interessados pelo assunto, considerando-se também aqueles que podem ter acesso via internet.

Já no espaço interno se identificam os protagonistas, em um processo de interpretação da linguagem: o enunciador, que é a pesquisadora, fala para seus destinatários e para os espectadores, que têm acesso ao material e o consultam. 
A pesquisadora Ana Amélia Camarano, conforme dados divulgados em sua página pessoal, tem pós-doutorado em Envelhecimento Populacional e Arranjos Familiares. É doutora em Estudos Populacionais e mestre em Demografia. Também, é Graduada em Economia e pesquisadora da Diretoria de Estudos e Políticas Sociais (DISOC) e do Instituto de Pesquisa Econômica Aplicada (IPEA), além de ser professora da Fundação Getúlio Vargas (FGV), conforme registrado em seu curriculum lattes e no Conselho Nacional de Desenvolvimento Científico e Tecnológico (CNPq).

\section{Finalidade do Discurso}

A finalidade do discurso da pesquisadora Ana Amélia Camarano é apresentar uma reflexão técnica sobre o Estatuto do Idoso e sugerir algumas mudanças, com vistas à sua adequação à realidade econômica e demográfica. Por ser pessoa muito conhecida no meio acadêmico, quando se trata de assuntos sobre envelhecimento e velhice, sua análise sobre o Estatuto é de grande valia para se avançar neste tema, além de dar indícios de como o idoso é percebido nesse contexto.

Conforme dados do Repositório do Conhecimento do IPEA, este texto, até abril de 2017, teve 1.343 visualizações no Brasil e um total de 1.776 visitas, considerando-se as de interessados de outros países, como Estados Unidos, China, Espanha, Portugal, entre outros.

\section{Estratégias de Ordem Enunciativa para Captar o Público}

Segundo Charaudeau (2008), a modalização é uma categoria de língua que reagrupa conjuntos de procedimentos estritamente linguísticos, os quais permitem explicitar o ponto de vista do locutor, que pode ser alocutivo, quando ele implica o interlocutor em seu ato de enunciação e lhe impõe o conteúdo de sua proposição; elocutivo, no caso de o locutor situar sua proposição em relação a si mesmo, num ato de enunciação; e delocutivo, que é verificado quando o locutor deixa a proposição se impor enquanto tal, como se ele não fosse absolutamente responsável. A modalização faz parte do fenômeno linguístico chamado de enunciação. Esta é constitutiva do ato que consiste em utilizar os elementos da língua para ordená-los em discurso, o que explica que a enunciação pertence à ordem do discurso.

O texto analisado "Estatuto do Idoso: avanços com contradições", escrito por Ana Amélia Camarano, se enquadra na modalidade "elocutiva", que, de acordo com Charaudeau (2008, p. 
83), se apresenta quando o sujeito falante enuncia seu ponto de vista "sem que o interlocutor esteja implicado nessa tomada de posição". Este tipo de enunciado revela o ponto de vista interno do sujeito falante e pode ser especificado como modos de saber, avaliação, motivação, engajamento e decisão. Constatou-se a presença do ponto de vista do modo de saber por meio da "constatação"; do ponto de vista de avaliação, correspondendo à modalidade de "opinião"; e do ponto de vista de engajamento, na modalidade "declaração" (CHARAUDEAU, 2008, p. 83).

Ao realizar uma constatação, Camarano mostra conhecimento sobre o assunto e seu propósito. Trata-se de reconhecer a realidade abordada no Estatuto do Idoso e se limitar a expor os fatos de maneira mais exterior e objetiva (CHARAUDEAU, 2008). Logo no início de seu texto, ela afirma que:

No Brasil, o Estatuto da Criança e do Adolescente (ECA) e o Estatuto do Idoso constituem um reconhecimento por parte do Estado de que estes grupos etários têm necessidades próprias e, por isto, são alvo de políticas públicas específicas (CAMARANO, 2013, p. 7).

Um pouco adiante, Camarano faz outra constatação a respeito do que é apresentado no Estatuto e também do que não está incluído nele, afirmando que:

O Estatuto do Idoso apresenta em uma única e ampla peça legal muitas das leis e políticas previamente aprovadas. Incorpora novos elementos e enfoques, dando um tratamento integral ao estabelecimento de medidas que visam proporcionar o bem-estar dos idosos e com uma visão de longo prazo (CAMARANO, 2013, p. 8).

Apesar de o Estatuto considerar que os seus beneficiários são pessoas que vivem a última fase da vida, o direito a uma morte digna não está incluído nos direitos assegurados por ele (CAMARANO, 2013, p. 9).

No que diz respeito a planos de saúde, a autora verifica que:

Dado que as mensalidades não podem ser aumentadas a partir dos 60 anos, para minimizar o risco da sua inviabilidade, as seguradoras estipulam um aumento proporcionalmente muito maior para aqueles que completam 59 anos comparativamente ao praticado para os grupos etários inferiores. Ao completar 54 anos, um indivíduo incorre em um aumento médio de $20 \%$ no valor a ser pago ao seu plano. Ao completar 59 anos, esse aumento passa para 70\% (CAMARANO, 2013, p. 14).

Silva e Rodrigues (2016), em estudo sobre a realidade de Portugal, também chamam atenção para o fato de que os idosos se encontram em uma fase da vida em que, na maioria das vezes, há aumento de gastos com saúde e a aposentadoria está associada a uma redução dos rendimentos, colocando-os numa situação deficitária. Da mesma forma, Camarano (2013) 
constata que a população em idade avançada tem como característica a perda da capacidade laborativa e de geração de renda, levando à criação dos sistemas de seguridade social. Fragoso (2016) confirma que a população ainda é percebida como vítima, carente e dependente e, portanto, objeto de assistência social em vez de um sujeito social de pleno direito. Marques (2011), por sua vez, considera que, mesmo que a situação material dos idosos tenha melhorado ao longo dos anos, as diversas políticas que têm sido postas em prática ainda contribuem para promover uma ideia negativa das pessoas idosas, considerando-as inúteis, doentes e incapazes.

Importante ressaltar que Mascaro (2004) já vislumbrava uma realidade que não pode ser esquecida e implica no fato de que o Brasil, sendo um país heterogêneo, cheio de contrastes e desigualdades econômicas e sociais, deveria levar isso em conta na hora de propor a reforma da Previdência Social, principalmente no que diz respeito à aposentadoria e ao sistema de saúde. Isso porque, conforme Abreu (2017), há pessoas que atingem o que a sociedade define como velhice e poderiam se aposentar, mas preferem manter-se ativas, pois não sofrem perdas cognitivas e nem encontram razões para deixar de trabalhar.

Camarano (2013) também constatou que o Estatuto responsabiliza a família pelo cuidado do idoso dependente e atribui ao Estado a função de fiscalizar e punir. Silva e Rodrigues (2016), tomando o exemplo de Portugal, sugerem que há necessidade de outros serviços de apoio às famílias, além de fiscalizar e punir, como supervisão contínua, telefonemas frequentes e visitas domiciliares de caráter social, feita até mesmo por voluntários e cuidadores informais, possibilitando mais bem-estar a essa população. No entanto, se nessa constatação Camarano se limita a não julgar, o mesmo não ocorre quando ela emite sua opinião, evidenciando sua avaliação sobre o Estatuto do Idoso, de modo a favorecer o entendimento de sua intenção e justificá-lo. Ao longo do texto, sua opinião foi percebida com convicção em alguns trechos e como suposição em outros. Por sua vez, ao emitir opinião, Charaudeau (2008, p. 92) ressalta que o locutor "explicita a posição que o fato ou a informação ocupam em seu universo de crenças. Assim, o locutor avalia a verdade de seu propósito e, ao mesmo tempo, revela qual é o seu ponto de vista". A convicção é uma atitude de crença em que há a expressão de certeza total a respeito da validade do propósito. Já na suposição se observa certeza forte ao pressentimento de algo (CHARAUDEAU, 2008).

Do ponto de vista avaliativo, Camarano utiliza-se da modalidade "opinião" em várias partes do seu texto, embasando as mudanças que ela sugere ao Estatuto. Para ela, é verdade que "o grande avanço do Estatuto do Idoso está na previsão do estabelecimento de crimes e sanções administrativas para o não cumprimento dos ditames legais" (CAMARANO, 2013, p. 9). Silva e 
Rodrigues (2016) corroboram a necessidade dessa proteção, uma vez que o crime e a violência, bem como a insegurança, são fatores importantes que interferem, negativamente, no bem-estar das pessoas, propiciando baixa saúde mental, isolamento, baixa autoestima e humor negativo.

Ainda nesse sentido, Marques (2011) reforça que o abuso contra as pessoas idosas pode ocorrer tanto em meios institucionais, como lares e hospitais, quanto em casa, sendo crime cometido por familiares ou por alguém próximo. Ele ainda chama a atenção para o idadismo, que diz respeito a atitudes e práticas negativas generalizadas em relação aos indivíduos, baseadas na sua idade, dizendo que estão relacionadas com menor empatia e possibilitam a ocorrência de maus tratos. Em seus estudos, ele considera o idadismo como forma de discriminação que não costuma ser socialmente sancionada.

Camacho e Alves (2015, p. 2), em sua pesquisa sobre maus tratos contra os idosos, fizeram menção ao Plano de Ação para o Enfrentamento da Violência Contra a Pessoa Idosa, cujo objetivo foi "promover ações que levem ao cumprimento do Estatuto do Idoso e do Plano de Ação Internacional para o Envelhecimento (ONU/2002) e que tratem do enfrentamento da exclusão social e de todas as formas de violência contra esse grupo social".

Ao abordar sobre os dispositivos que asseguram meia-entrada nas atividades culturais e de lazer e gratuidade nos transportes coletivos, Camarano está convicta de que:

No entanto, o que se considera mais importante, nesse caso, é o fato de o estatuto não ter estipulado fontes de financiamento para os dispositivos estabelecidos, o que está resultando no encarecimento generalizado das entradas de cinema, teatro, eventos esportivos e transporte público (CAMARANO, 2013, p. 13).

Essa opinião convicta sobre esse assunto é seguida de uma suposição, um pressentimento, em que ela afirma que "os custos decorrentes dessa redução de tarifas estão sendo compartilhados com toda a sociedade, o que pode gerar conflitos intergeracionais" (CAMARANO, 2013, p. 14). Nesse mesmo sentido, ao tratar da ampliação da cobertura da assistência à saúde e sobre os custos que essa ação gera, com necessidade de retirar recursos de outras áreas, novamente essa autora supõe que "como em outras situações, um dos resultados não previstos pode ser a geração de conflitos intergeracionais" (CAMARANO, 2013, p. 20). Para tanto, Marques (2011) sugere a promoção de ações intergeracionais que permitam o contato positivo entre pessoas idosas e outros grupos etários, o que ele considera muito importante para diminuir atitudes idadistas. Por sua vez, Carmagnanis (2016) constatou em sua pesquisa que também os idosos querem estar mais próximos das gerações mais jovens, com o intuito de ensinar e aprender, a fim de que os jovens construam uma imagem positiva deles. $O$ 
que se percebe então, conforme Abreu (2017), é que evitar conflitos intergeracionais e, por sua vez, favorecer a convivência entre as gerações propiciam a partilha de ideias e estabelecem cooperação saudável, preparando um futuro sem discriminação e exclusão social.

Continuando sua exposição sobre o que diz respeito ao direito à saúde e à vida, Camarano pontua que:

É inegável a importância do direito à saúde e à vida, mas dado que essa peça legal referese às pessoas que vivenciam a última fase da vida, é importante que se inclua, também, o direito a uma morte digna. Para isto, os sistemas de saúde devem estar preparados para garantir uma morte digna para todos quando chegar o momento (CAMARANO, 2013, p. 20).

Ainda expondo sua opinião, no que diz respeito aos assentos destinados aos idosos nos veículos de transporte público, Camarano (2013, p. 16) questiona a obrigatoriedade dessa reserva, que parece desresponsabilizar os indivíduos no tocante a ajudar quem precisa, de modo que "isto pode agir como um desincentivo à formação de uma cultura de solidariedade na sociedade brasileira". Pinto (2016) menciona isso, apontando que o contraste entre a realidade dos mais velhos e a dos mais jovens faz com que estes últimos interpretam que os idosos possuem regalias injustas, convertendo a solidariedade intergeracional em conflito de gerações. Nesse mesmo sentido, Azeredo (2016) ressalta que, embora os aspectos normativos devam mudar com o tempo, o respeito pelo outro e a solidariedade devem estar sempre presentes nas atitudes e comportamentos dos cidadãos.

Pode-se dizer também que as mudanças no Estatuto, sugeridas por Camarano, partem de sua convicção acerca do assunto e de que a implementação do Estatuto do Idoso deve ser pensada em contexto que leve em consideração ações que busquem a proteção social para os vários grupos etários. Para ela, o reconhecimento de necessidades específicas, no que diz respeito aos idosos, não justifica preconceitos nem privilégios, pois eles não vivem isolados. Além disso, Teixeira (2002) reforça que o papel das políticas públicas é atender às demandas dos setores mais vulneráveis da sociedade, principalmente, bem como ampliar e efetivar direitos de cidadania, gestados nas lutas sociais e reconhecidos institucionalmente. Assim, Azeredo (2016) afirma que qualquer política pública deve ser acompanhada de debates públicos, envolvendo a população local, para motivar a participação e para que haja proximidade com as realidades social e sanitária locais. 
No entendimento de Camarano, as mudanças são necessárias, e a primeira deve ser a alteração na idade que define a população idosa, devendo passar de 60 para 65 anos. Outros pontos a serem considerados são:

\begin{abstract}
Estabelecimento de fontes de financiamento para cada medida proposta, medidas que ajudem a família a cuidar do idoso dependente tanto no domicílio quanto no hospital, inclusão nos serviços de saúde de ações que possam promover uma morte digna para aqueles que se encontram acometidos por uma doença terminal (CAMARANO, 2013, p. 24-25).
\end{abstract}

Mascaro (2004) abordou sobre a necessidade de o Estado realizar planos e estratégias para o fortalecimento da família, para que o idoso tenha condições de viver uma velhice digna. Embora o contexto econômico e social tenha propiciado mudanças na dinâmica familiar, o auxílio às famílias cuidadoras pode significar, também, maior bem-estar ao idoso. Conforme relatam Honório et al. (2016), em situação em que a institucionalização se faz necessária por falta de condições pode acontecer que, sem o apoio familiar desejado, o idoso sinta-se frustrado pelo desajuste das trocas. Silva e Rodrigues (2016) corroboram esse fato, afirmando que, quando a família tem capacidade para se tornar cuidadora, pode-se esperar um idoso integrado, com maior longevidade e qualidade de vida.

Pensar em morte digna significa considerar o indivíduo como um todo e não somente como um corpo que padece e chega ao fim. Laranjeira (2016, p. 92) chama a atenção para o fato de que "a exaltação da juventude e da beleza acaba por rejeitar o corpo envelhecido, encarando-o como decrépito e em estado de declínio". E vai além, afirmando que:

O corpo é finito, mas os filhos e netos ficam e isso demonstra uma tentativa de transcendência da existência, a qual revitaliza não só o corpo, mas a própria existência. Os valores afetivos ganham assim uma nova roupagem, pois passam a ideia de que o que valeu a pena está, pois destinado à eternidade. Assim, a morte não representa o contrário da vida, pois é o contrário do nascimento, logo a vida não tem contrários. A morte faz parte da vida e como a velhice remete para a finitude, acharam por bem eliminá-la (LARANJEIRA, 2016, p. 100).

Retomando as categorias modais identificadas no discurso de Ana Amélia Camarano, a "declaração" foi percebida ao se detectar o grau de adesão da autora em relação ao Estatuto. De acordo com Charaudeau (2008), ao declarar algo, o locutor, que detém o saber, supõe que o interlocutor ignora ou duvida da verdade, buscando elucidá-la, e essa declaração pode se desdobrar em confissão, revelação, afirmação e confirmação. Assim, verifica-se que Camarano (2013, p. 11) declara, com a variante afirmação, que "como toda classificação, a de 'idoso' 
simplifica a heterogeneidade desse segmento e, por isso, está sujeita a incluir indivíduos que não necessitam de tais políticas ou a excluir aqueles que necessitam".

No desejo de contribuir para mostrar a realidade, no que diz respeito à redução da idade mínima para recebimento do Benefício de Prestação Continuada (de 67 para 65 anos), a autora também declara que:

\begin{abstract}
A equiparação da idade mínima requerida para esse benefício com a requerida para o de aposentadoria por idade dos trabalhadores urbanos do sexo masculino não foi muito bem aceita por uma parte dos economistas do setor público. Estes acreditam que ela pode agir como um fator de desincentivo à contribuição para o sistema previdenciário, principalmente entre os trabalhadores de baixa renda (CAMARANO, 2013, p. 17-18).
\end{abstract}

Camarano (2013) também deixa claro que a solidariedade entre as gerações deve ser promovida ao se fazer política para a população idosa. Afirma então que "isto significa equilibrar as prioridades das ações para os idosos com a de outros grupos populacionais.

\title{
Procedimentos da Lógica Argumentativa
}

Freitas (2009) salienta que a competência semiolinguística, conforme a proposição de Charaudeau, postula que todo sujeito que se comunica e interpreta pode manipular e identificar a forma dos signos, suas regras combinatórias e seu sentido, reconhecendo seu uso para expressar a intenção de comunicação, de acordo com os elementos do marco situacional e as exigências da organização do discurso.

A exposição aparece em forma de argumentação. Quem argumenta, de acordo com Charaudeau (2008), dirige-se, com convicção, a um interlocutor que raciocina, que tem a capacidade de refletir e compreender, com o objetivo de persuadi-lo a modificar seu comportamento. Ele propõe que os argumentos sejam divididos em modos de raciocínio, que se inscrevem em determinada encenação argumentativa para se combinarem com os componentes desta encenação. Esses modos de raciocínio podem ser: Dedução (por silogismo, pragmática, condicional), Explicação (por silogismo, pragmática, por cálculo, hipotética), Associação (dos contrários, do idêntico), Escolha Alternativa (incompatibilidade, escolha entre positivo/negativo, escolha entre duas negativas, escolha entre duas positivas) e Concessão Restritiva (CHARAUDEAU, 2008). 
O texto da Ana Amélia Camarano enquadra-se no modo de raciocínio baseado na Concessão Restritiva, Dedução por Cálculo, Explicação Pragmática e Associação dos Contrários.

A Concessão Restritiva, de acordo com Charaudeau (2008), consiste em aceitar uma asserção de partida, mas contestar que ela possa levar à conclusão proposta. Assim, Camarano, embora reconheça que o Estatuto representa avanço no que diz respeito a políticas sociais de inclusão dos idosos, salienta que, para de fato isso acontecer, algumas mudanças devem ser feitas. Ela argumenta sua declaração acerca das políticas para a população idosa e sua convicção de que o bem-estar desse segmento depende do bem-estar de toda a sociedade, fazendo uma concessão restritiva, ao argumentar que:

\begin{abstract}
Não se tem dúvida da importância de políticas diferenciadas para cada fase da vida, pois cada uma delas tem demandas e necessidades específicas. No caso da população idosa, as condições de saúde/autonomia têm um papel fundamental na determinação dessas demandas. No entanto, o seu reconhecimento não justifica a existência de preconceitos, nem de privilégios para os idosos, pois estes não vivem isolados na sociedade (CAMARANO, 2013, p. 23-24).
\end{abstract}

A Dedução, por sua vez, consiste em um modo de raciocínio em que há relação de "causalidade orientada da causa para a consequência". Dessa forma, a dedução por cálculo tem "vínculo modal pertencente ao eixo do possível (probabilidade) e também o escopo de uma hipótese que tende a se tornar generalização (CHARAUDEAU, 2008, p. 214). Camarano utiliza esse modo ao falar do Estatuto, deduzindo que "ao considerar a população como um subgrupo populacional demandante de regras específicas está se assumindo que a sua capacidade de conseguir resultados é diferente da de outros grupos etários" (CAMARANO, 2013, p. 9). Em outro momento, também seguindo esse modo de raciocínio, ela verifica que:

Resumindo, os benefícios que visam compensar os idosos pela sua 'pobreza', terminam não os beneficiando e impondo custos adicionais para o restante da sociedade. Ou seja, é uma medida que não beneficia ninguém, tendo em vista que a lógica das seguradoras privadas é o lucro (CAMARANO, 2013, p. 15).

A explicação, por sua vez, de acordo com Charaudeau (2008, p. 215), é um modo de raciocínio simétrico à dedução; no entanto, há "relação de causalidade que é orientada da consequência para a causa". A explicação pragmática baseia-se no modo de encadeamento causal, com vínculo modal pertencente ao eixo do necessário. A causa pode ser pontual, um 
desejo ou uma experiência pessoal (CHARAUDEAU, 2008). Ao falar a respeito da definição da população idosa, Camarano (2013, p. 10) argumenta que:

\begin{abstract}
Esse aumento da esperança de vida e as mudanças nos papéis dos idosos implicam uma rediscussão do conceito de 'idoso'. Duas questões se colocam. A primeira advém do critério utilizado para separar indivíduos nas várias fases da vida. A segunda está relacionada ao conteúdo da classificação de um indivíduo como idoso.
\end{abstract}

No Estatuto, idoso é todo aquele que possui 60 anos ou mais de idade. De modo geral, os idosos são tratados como pessoas com necessidades iguais, frágeis e dependentes. O critério da idade biológica coloca todos como alvo das ações propostas, desconsiderando suas particularidades. Camarano, por sua vez, considera que a classificação etária por si só não dá conta de atender às necessidades dos idosos, subestimando ou superestimando suas reais demandas. Esse critério cronológico não leva em conta a individualidade e as condições econômicas, familiares, culturais, sociais e de saúde. Esse mesmo modo de pensar é compartilhado por diversos autores, entre eles Marques (2011), que reforça que a idade cronológica não é o melhor indicador do processo individual de envelhecimento e que mesmo a medicina tem considerado, muitas vezes, outros indicadores, como a idade biológica, chegando a constatar que a maioria das pessoas idosas apresenta autonomia e independência funcional até mais tarde.

Nesse sentido, Laranjeira (2016) destaca que as pessoas entram na idade avançada com idades diferentes, uns com 80, outros com 90 anos e há aqueles que, mesmo sem doença, são marcados pelos sinais da idade avançada desde os 60 anos, significando que o conceito cronológico do idoso é tão somente uma função linear da expectativa de vida. Mascaro (2004) também considera que, embora a idade cronológica seja um indicador impreciso, tendo em vista que o envelhecimento é um processo biológico, social e psicológico, a data de aniversário é o principal critério para situar as categorias etárias. Foi ponderando essa realidade que Limoeiro (2016, p. 109) direcionou sua pesquisa, com o propósito de investigar como as pessoas de diferentes faixas etárias percebem o envelhecimento, com a justificativa de que, embora entenda que as ideias de juventude ou velhice são construídas socialmente, levou em consideração o fato de que "as idades constituem referências fundamentais para a inserção dos indivíduos na sociedade moderna".

Marques (2011) também concorda que os limites cronológicos associados aos jovens, pessoas de meia-idade e idosos são construídos socialmente e podem variar de uma sociedade para outra. Quaresma (2008, p. 3) aborda a idade como uma construção social subjetiva e propõe 
que cada um pode ter várias idades, simultaneamente: idade social, idade sociogeracional, idade biológica, idade cronológica, entre outras.

Embora a classificação por idades seja útil para compreender melhor o mundo, organizando os papéis e os deveres dos diversos membros da sociedade, ela também pode ter efeito negativo, pois torna todas as pessoas de uma mesma categoria etária muito semelhantes, contribuindo para aumentar ainda mais a percepção homogênea e estereotipada. Igualmente, Abreu (2017) afirma que a fidedignidade da classificação cronológica tem forte complicador:

O transcorrer do tempo não gera consequências uniformes em todos. As diferenças individuais entre pessoas idosas são enormes e abraçam fatores genéticos, psicológicos e ambientais. Essas modificações, que vão se estabelecendo durante a passagem do tempo de uma vida, constituem um processo complexo e multifacetado (ABREU, 2017, p. 39).

A visão limitada sobre o idoso foi novamente retomada por Camarano, ao falar que um dos critérios definidores de políticas públicas é a visão que se tem do público-alvo, afirmando que:

O impacto do envelhecimento populacional no desenvolvimento econômico e a necessidade de políticas públicas são fortemente afetados pelas condições de saúde e autonomia da população idosa. O estereótipo de idosos como um grupo homogêneo com necessidades especiais tem predominado nas políticas públicas (CAMARANO, 2013, p. 12).

Em relação a estereótipos, Marques (2011) afirma que eles estão ligados à tendência de perceber todas as pessoas de determinada idade como grupo homogêneo, caracterizado, frequentemente, por traços negativos, como incapacidade e doença. Camarano retomou um fato evidente nas políticas públicas, explicando que as medidas tomadas levam em consideração a percepção de que todos os idosos são frágeis e possuem necessidades especiais. Na contramão desse modo de perceber a população idosa, Laranjeira (2016) considera que medidas de segurança e apoio aos idosos devem levar em conta aspectos históricos, sociais, econômicos e culturais, de modo a não tratar esta população de forma homogênea, pois cada indivíduo tem percepção diferente do seu processo de envelhecimento. Igualmente, Marinho et al. (2016) evidenciaram a necessidade de que novos tratamentos e significados sejam construídos para que não haja generalizações sobre a velhice, também nas práticas profissionais, e que esses sujeitos histórico-sociais não sejam reduzidos a aspectos biológicos. 
Outro modo de raciocínio previsto na lógica argumentativa é a associação, que se caracteriza por colocar a premissa e sua conclusão numa relação de contrário ou identidade (CHARAUDEAU, 2008). Na análise do documento técnico, percebe-se que a associação dos contrários está contemplada no discurso de Camarano (2013, p. 23), quando destaca que "apesar de o envelhecimento populacional ser reconhecido como uma das principais conquistas sociais do século XX, sabe-se, também, que este traz grandes desafios para as políticas públicas, a sociedade e a família".

Notou-se que os argumentos utilizados pela referida pesquisadora estão em consonância com o discurso econômico do IPEA, em prol de um Brasil desenvolvido. Suas sugestões se baseiam no Plano de Madri, que tem como "uma de suas três metas a participação ativa dos idosos na sociedade e no desenvolvimento econômico" (CAMARANO, 2013, p. 24).

A participação ativa dos idosos, por sua vez, tem apoio no envelhecimento ativo, definido pela Organização Mundial da Saúde (2005, p. 13) como um "processo de otimização das oportunidades de saúde, participação e segurança, com o objetivo de melhorar a qualidade de vida à medida que as pessoas ficam mais velhas". Fato esse que permite que as pessoas percebam o seu potencial para o bem-estar físico, social e mental, participando da sociedade de acordo com suas necessidades, desejos e capacidades, com proteção, segurança e cuidados adequados, quando necessários. Para Silva e Rodrigues (2016), o conceito de vida ativa está implícito no processo de envelhecimento ativo, que deve ser iniciado na idade jovem e prolongarse durante toda a vida.

Ainda sobre a participação ativa, Pinto (2016) lembrou o fato de que, em 2004, a Comissão Europeia retomou a Agenda de Lisboa, aprovada em 2000, que tinha como objetivo tornar a União Europeia a economia mais competitiva do mundo, reiterando, entre outras prioridades, a ideia de promover o prolongamento da vida ativa. Nesse contexto, porém, vida ativa significava sobrevivência e competição na esfera do trabalho, de modo que os idosos deveriam retardar sua aposentadoria ao máximo, pois, ao saírem, seriam considerados inúteis e peso para a sociedade, uma vez que não seriam mais capazes de produzir sequer o que consumiam. Seguiam, dessa forma, uma linha de passividade em que deveriam se adaptar aos imperativos deste paradigma preexistente. No entanto, o que se propõe, na visão daquele autor, é um novo paradigma, que vai ao encontro do conceito de envelhecimento ativo proposto pela Organização Mundial da Saúde. Esse novo paradigma consiste no fato de que não é o sujeito quem deve se adequar à realidade, mas esta que deve se modificar, pela intervenção humana, e então proporcionar melhores condições para que a humanidade possa progredir no sentido de sua realização. Dessa 
forma, a aposentadoria deixaria de ser compreendida como o começo de uma vida inútil; pelo contrário, ao se libertar das obrigações profissionais, ganhariam disponibilidade total para as várias atividades de cidadania e cultura.

\section{CONSIDERAÇÕES FINAIS}

A análise semiolinguística realizada sobre a percepção do envelhecimento e da velhice trazida neste dispositivo técnico trouxe à tona o imaginário sobre o idoso, que foi defendido no discurso da Ana Amélia Camarano como cidadão de direitos e deveres, cujas necessidades variam conforme suas condições socioeconômicas, culturais, familiares e de saúde. Esses argumentos foram utilizados para retratar essa etapa da vida, e as técnicas argumentativas foram empregadas para convencer o leitor.

As mudanças propostas para o Estatuto do Idoso estão diretamente relacionadas COM AS $\underline{\underline{a}}$ questões econômicas, como idade para aposentadoria, recebimento de benefícios e fontes de financiamento para as medidas propostas, sem deixar de lado as questões sociais que envolvem essa realidade, que dizem respeito à proteção social, à intergeracionalidade e à atenção à família e ao cuidador do idoso, além da sua inclusão nos serviços de saúde, bem como de ações que respeitem o direito de morte digna quando acometido de doença terminal.

O discurso da Ana Amélia Camarano deixou a entender que o Estatuto do Idoso trouxe, de fato, avanços no que diz respeito a como o idoso deve ser tratado na sociedade, mas trouxe também contradições ao propor medidas que podem gerar conflitos intergeracionais, uma vez que generaliza todos os indivíduos pertencentes a essa faixa etária, além de não especificar a fonte de financiamento para tais medidas.

A análise semiolinguística do dispositivo técnico permitiu inferir que a percepção do idoso é de alguém que vivencia a última fase da vida, que tem necessidades específicas, mas que não devem ser alvos de preconceitos nem de privilégios. Para Camarano, os idosos fazem parte de um segmento populacional com características heterogêneas e que não vivem isolados na sociedade. A família do idoso dependente deve receber apoio do poder público, assim como as ações voltadas para os idosos devem ser equilibradas e direcionadas a outros grupos populacionais, de modo a promover a solidariedade entre as gerações.

Enfim, pode-se concluir que Camarano, com seu discurso, contribuiu para melhor reflexão sobre políticas públicas de modo geral e, especificamente, para se pensar o idoso na sociedade 
contemporânea, de natureza imediatista e pragmática, com reflexos sobre a compreensão social do envelhecimento e da velhice.

\section{REFERÊNCIAS}

ABREU, Maria Celia de. Velhice: uma nova paisagem. São Paulo: Ágora, 2017. Google

ALVINO, Fábio Soares. Concepções do idoso em um país que envelhece: reflexões sobre protagonismo, cidadania e direitos humanos no envelhecimento. 2015. 145 f. Dissertação (Mestrado em Direitos Humanos e Cidadania) - Universidade de Brasília, Brasília, 2015. [Visualizar] Google

AZEREDO, Zaida. Cultura, Cidadania e Envelhecimento. In: AZEREDO, Zaida (coord). Envelhecimento, Cultura e Cidadania. Lisboa: Edições Piaget, 2016.

AZEREDO, Zaida. Plano Educativo Local: preservador da cultura e promotor de saúde e cidadania. In: AZEREDO, Zaida (Coord.). Envelhecimento, Cultura e Cidadania. Lisboa: Edições Piaget, 2016.

BARROS, Ricardo Paes de; MENDONÇA, Rosane; SANTOS, Daniel. Incidência e natureza da pobreza entre idosos no Brasil. Rio de Janeiro: IPEA, 1999. [Visualizar] Google

BRITO, Maria da Conceição Coelho; FREITAS, Cibelly Aliny Siqueira Lima; VASCONCELOS, Maristela Inês Osawa; DIAS, Maria do Socorro; SANTIAGO, Luciana Maria Montenegro; GOMES, Diógenes Farias. Atenção à saúde do idoso e família: evidências da produção científica. Kairós Gerontologia, v. 17, n. 1, p. 87-101, 2014. [Visualizar] Google

CALDAS, Célia Pereira; THOMAZ, Andrea Fernandes. A Velhice no Olhar do Outro: Uma perspectiva do jovem sobre o que é ser velho. Kairós Gerontologia, v. 13, n. 2, p. 75-89, 2010. [Visualizar] Google

CAMACHO, Alessandra Conceição Leite Funchal; ALVES, Rosemere Rosa. Maus tratos contra os idosos na perspectiva da enfermagem: revisão integrativa. Revista de enfermagem UFPE, v. 9, n. 2, p. 927-935, 2015. Google

CAMARANO, Ana Amélia; KANSO, Solange. As instituições de longa permanência para idosos no Brasil. Revista Brasileira de Estudos de População, v. 27, n. 1, p. 232-235, 2010. crossref Google

; MELLO, Juliana Leitão. Como vive o idoso brasileiro. In: CAMARANO, Ana Amélia (org.). Muito além dos 60: os novos idosos brasileiros, Rio de Janeiro: IPEA, p. 27-73, 1999.

Estatuto do idoso: avanços com contradições. Rio de Janeiro: IPEA, 2013. Google

CAMARGOS, Mirela Castro Santos; MACHADO, Carla Jorge; RODRIGUES, Roberto Nascimento. A relação entre renda e morar sozinha para idosas mineiras, 2003. In: Seminário Sobre a Economia Mineira, v. 12, p. 1-14, Diamantina, 2006. 
CARADEC, Vincent. Da Terceira Idade à Idade Avançada: a conquista da velhice. In: GOLDENBERG, Mirian (org.). Velho é Lindo!. Rio de Janeiro: Civilização Brasileira, 2016.

CARMAGNANIS, Fernanda. Jovens há Mais Tempo. In: GOLDENBERG, Mirian (org.). Velho é Lindo!. Rio de Janeiro: Civilização Brasileira, 2016.

CHARAUDEAU, Patrick. Linguagem e discurso: modos de organização. São Paulo: Editora Contexto, 2008. Google

CHARAUDEAU, Patrick. Uma análise semiolinguística do texto e do discurso. In: PAULIUKONIS, M. A. L. e GAVAZZI, S. (Orgs.) Da língua ao discurso: reflexões para o ensino. Rio de Janeiro: Lucerna, 2005, p. 11-27.

FIGUEIREDO, Maria Henriqueta de Jesus Silva; MARTINS, Maria Manuela Ferreira Pereira da Silva; SILVA, Luzia Wilma Santana da; OLIVEIRA, Palmira da Conceição Martins de. Ciclo vital da família e envelhecimento: contextos e desafios. Kairós Gerontologia, v. 14, p. 11-22, 2011. Google

FLORES, Gisela Cataldi; BORGES, Zulmira Newlands; DENARDIN-BUDÓ; Maria de Lourdes; MATTIONI, Fernanda Carlise. Cuidado intergeracional com o idoso: autonomia do idoso e presença do cuidador. Revista Gaúcha de Enfermagem, v. 31, n. 3, p. 467-474, 2010. crossref Google

FRAGOSO, Vitor. Gerontologia Crítica como Prática de Emancipação. In: AZEREDO, Zaida (coord). Envelhecimento, Cultura e Cidadania. Lisboa: Edições Piaget, 2016.

FREITAS, Ernani Cesar de. A semiolinguística no discurso: práticas de linguagem em situações de trabalho. Revista do Programa de Pós-Graduação em Letras da Universidade de Passo Fundo, v. 4, n. 2, p. 262-283 - jul./dez. 2009.

HONÓRIO, Samuel; BATISTA, Marco; MARTINS, Júlio; PAULO, Rui; SERRANO, João; PETRICA, João. A Importância de uma Cultura de Exercício Físico para o Idoso. In: AZEREDO, Zaida (coord). Envelhecimento, Cultura e Cidadania. Lisboa: Edições Piaget, 2016.

IBGE. Síntese de Indicadores sociais: uma análise das condições de vida da população brasileira. Rio de Janeiro: IBGE, 2015. Acesso em: 19 set 2017. [Visualizar]

JARDIM, Viviane Cristina Fonseca da Silva; MEDEIROS, Bartolomeu Figueiroa de; BRITO, Ana Maria de. Um olhar sobre o processo do envelhecimento: a percepção de idosos sobre a velhice.

Rev. Bras. Geriatr. Gerontol., v. 9, n. 2, p. 25-34, 2006. Google

JOIA, Luciane Cristina; RUIZ, Tania; DONALISIO, Maria Rita. Condições associadas ao grau de satisfação com a vida entre a população de idosos. Revista de Saúde Pública, v. 41, n.1, p. 131-138, 2007. Google crossref

LARANJEIRA, Carlos. O Lugar do Corpo no Crepúsculo da Idade. In: AZEREDO, Zaida (coord). Envelhecimento, Cultura e Cidadania. Lisboa: Edições Piaget, 2016. 
LIMA, Cristina Rodrigues. Programas intergeracionais: um estudo sobre as atividades que aproximam as diversas gerações. 2007. 285f. Dissertação (Mestrado em Gerontologia) Universidade Estadual de Campinas, Faculdade de Educação, Campinas, SP, 2007.

LIMOEIRO. Beatrice Cavalcante. O Envelhecimento e as Mudanças no Corpo: novas preocupações e velhas angústias. In: GOLDENBERG, Mirian (org.). Velho é Lindo!. Rio de Janeiro: Civilização Brasileira, 2016.

MAFRA, Simone Caldas Tavares; SILVA, Emília Pinto da; FONSECA, Estela da Silva; ALMEIDA, Alessandra Vieira de; FREITAS, Núbia Cristina de. O envelhecimento nas diferentes regiões do Brasil: uma discussão a partir do censo demográfico de 2010. In: VI Workshop de Análise Ergonômica do Trabalho, III Encontro mineiro de Estudos em Ergonomia e VIII simpósio do Programa de Educação Tutorial em Economia Doméstica - Envelhecimento: como pensar o trabalho, a sociedade e as cidades? Jul 18, Anais, Viçosa-MG, 2013.

MARINHO, Maykon dos Santos; CHAVES, Renato Novaes; SOUZA FILHO, Argemiro Ribeiro; REIS, Luciana Araújo. Identidades de Idosos Longevos: significados atribuídos a ser velho. Argumentum, v.8, n. 3, p-146-158, 2016. Google

MARQUES, Filipa D.; SOUSA, Liliana. Agregado familiar de casais idosos: estrutura, dinâmicas e valores. Kairós Gerontologia, v. 15, p. 177-198, 2012. Google

MARQUES, Sibila. Discriminação na Terceira Idade. Lisboa: Fundação Francisco Manoel dos Santos, 2011.

MASCARO, Sonia de Amorim. O Que é Velhice. 2. ed. São Paulo: Brasiliense, 2004.

MELCHIOREE, Maria Gabriella; CHIATTI, Carlos; LAMURA, Giovanni; TORRES-GONZALES, Francisco; STANKUNAS, Mindaugas; LINDERT, Jutta; LOANNIDI-KAPOLOU, Elisabeth, BARROS, Henrique; MACASSA, Gloria; SOARES, Joaquim F. J.; Social support, socio-economic status, health and abuse among older people in seven European countries. PloS One, v. 8, n. 1, p. 1-10, 2013. Google crossref

ORGANIZAÇÃO MUNDIAL DA SAÚDE. Envelhecimento Ativo: uma política de saúde. Brasília: Organização Pan-Americana da Saúde, 2005. Google

PINTO, Fernando Cabral. Paradigmas Sociais do Envelhecimento. In: AZEREDO, Zaida (Coord.). Envelhecimento, Cultura e Cidadania. Lisboa: Edições Piaget, 2016.

QUARESMA, Maria de Lourdes. Questões do envelhecimento nas sociedades contemporâneas. Kairós Gerontologia, v. 11, n. 2, p.21-47, 2008. Google

REBOUÇAS, Monica; MATOS, Marina Ruiz; RAMOS, Luiz Roberto; CECÍLIO, Luiz Carlos de Oliveira. O que há de novo em ser velho. Saúde e Sociedade, v. 22, n. 4, p.1226-1235, 2013. Google

SILVA, Cileuza Alves Moreira; ALMEIDA, Andréia. A Importância da Família no Cuidado ao Idoso. Seminário Integrado, v. 6, n. 6, p. 1-12, 2015. 
SILVA, Marina da Cruz. O processo de envelhecimento no Brasil: desafios e perspectivas. Revista Textos sobre Envelhecimento, v. 8, n. 1, p. 43-60, 2005. Google

SILVA, Silvia Manuela Dias Tavares da; RODRIGUES, Rogério Manuel Clemente Rodrigues. Os Determinantes do Envelhecimento: a ruralidade e a urbanidade. In: AZEREDO, Zaida (coord). Envelhecimento, Cultura e Cidadania. Lisboa: Edições Piaget, 2016.

SIQUEIRA, Renata Lopes de; BOTELHO, Maria Izabel Vieira; COELHO, France Maria Gontijo. A velhice: algumas considerações teóricas e conceituais. Ciência \& saúde coletiva, v. 7, n. 4, p. 899-906, 2002. Google crossref

SOUZA, Rosangela Ferreira de; SKUBS, Thais; BRÊTAS, Ana Cristina Passarella. Envelhecimento e família: uma nova perspectiva para o cuidado de enfermagem. Revista Brasileira de Enfermagem, v. 60, n. 3, p. 263-267, 2007. Google crossref

TEIXEIRA, Elenaldo Celso. O Papel das Políticas Públicas no Desenvolvimento Local e na Transformação da Realidade. 2002. Associação dos Advogados de Trabalhadores Rurais da Bahia. Acesso em: 07 out. 2017. [Visualizar]

VERAS, Renato. Envelhecimento populacional contemporâneo: demandas, desafios e inovações. Revista de Saúde Pública, v. 43, n. 3, p. 548-554, 2009. Google crossref 